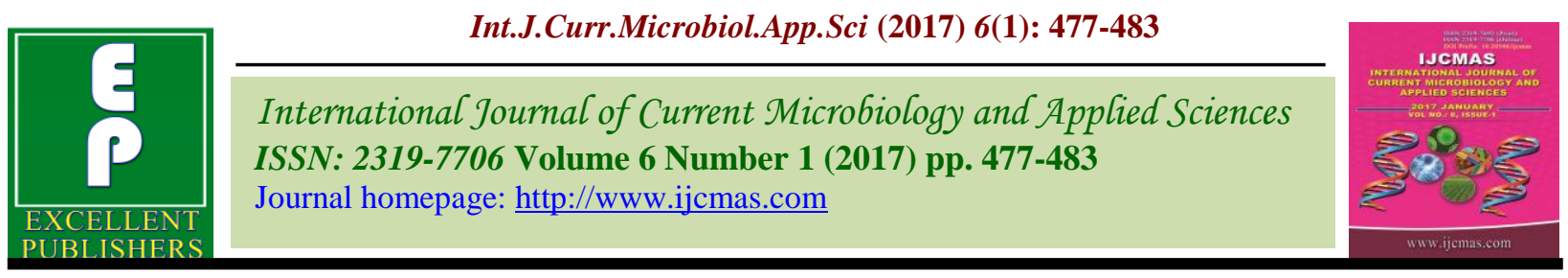

Original Research Article

http://dx.doi.org/10.20546/ijcmas.2017.601.056

\title{
Epidemiological Study of Cutaneous Leishmaniasis in Tuz
}

\author{
Shujan R. Hassan* \\ Department of Biology/College of Education for Pure Sciences/ Kirkuk University, Kirkuk/Iraq \\ *Corresponding author
}

\section{A B S T R A C T}

Keywords

Epidemio-

serological of

Cutaneous

Leishmaniasis,

AL-TUZ.

Article Info

Accepted:

23 December 2016

Available Online:

10 January 2017
A total of 107 Cutaneous leishmaniasis patients studied during the period from October 2012- april 2013 in TUZ General Hospital. They were 57\% males, their ages ranged from 1-60 years old. Clinically, 58\% of patients had multiple lesions, while $42 \%$ had single lesion. It was found that $36.5 \%$ of patients had dry type while $63.5 \%$ had wet type lesion. The highest rate of lesion was on upper limbs $57 \%$ while the lowest rate in the ear $1 \%$. Highest rate of cases were recorded during February $32.1 \%$ while lowest rate of cases were recorded in April 3,37\%. According to cultures and smears $73 \%$ of cases were positive to giemsa stain and $43 \%$ were positive in cultures. Secondary bacterial infection occurred in $42 \%$ of lesions; Staphylococcus epidermidis $55 \%$ was the most common bacteria isolated from lesions, followed by Staphylococcus aureus $33 \%$.

\section{Introduction}

Leishmaniasis is endemic in 88 countries throughout Africa, Asia, Europe and North and South America (Dedet et al., 2003). There are an estimated 12 million cases worldwide and there are about 1.5 million new cases of cutaneous leishmaniasis (CL) each year of which over $90 \%$ occur in Afghanistan, Algeria, Iran, Iraq, Saudi Arabia, Syria, Brazil and Peru (Ashford et al., 1992). Old World disease primarily is caused by Leishmania tropica in urban areas and Leishmania major in dry desert areas (William, 2004). In Iraq Two species are presnt in Iraq: L. tropica, agent of anthroponotic CL, L, major, agent of zoonotic CL. Both ACL and ZCL occur in Iraq.ACL is mainly suburban (Communicable Disease
Control, 2003). CL burden in Iraq, number of cases reported (incidence rate per 100,000): in 2001: is 625 cases and in 2000 is: 955 cases. While in the following years the (incidence rate per 100,000 increased (Ala, 2004). To determine the prevalence of CL in AL-TUZ General Hospital and to clarify the secondary bacterial infection in CL and its effect on natural history of disease.

\section{Materials and Methods}

A total of 107 patients infected with CL were included in this study during the period between October 2012 to April /2013 in the dermatology out-patients clinic of AL-TUZ General Hospital in AL-TUZ district. 
Although CL infect all age groups, the patients were divided in to two groups according to development of immune system and due to different requirement of $\mathrm{Zn}$ diet for maturation and growth for all age groups.

\section{Results and Discussion}

From the total of 107 patients with CL were included in the study, $57 \%$ of patients were male, while $43 \%$ were female (figure 1)

CL patients were included in this study their ages ranging between 1-60 years old,43\% of them their ages ranging between 1-15 years old and $57 \%$ were ages above 15 years old (Figure 2).

The male patients above 15 years $25.23 \%$ from 107 and their ages ranging between 1652 years old and female patients above 15 years old 31.7\% from 107 patients and their ages ranging between 16-60. Male patients $\leq$ 15 years old $31.7 \%$ from 107 patients which were their ages ranging between 2-15 years and female patients $\leq 15$ years old $11.21 \%$ from107 patients which their ages ranging between (1-15) years old (Figure 3).

Regarding to the type lesions and distribution of CL lesions on the skin of patients. It was found that $58 \%$ had multiple lesions, while $42 \%$ had single lesions (figure 4 ).

The highest number of skin lesion was 10 lesions. The total number of skin lesion in all CL patients were 187 lesions both nodular (Dry type) $36.50 \%$ and ulcerative (wet type) $63.50 \%$ (figure 5).

It was found that the most lesion were present on exposed area of the body. The result show that $57 \%$ of lesion were on upper limbs, $25 \%$ on the face, $15 \%$ on the lower limbs, $2 \%$ on the scalp and $1 \%$ on the ear as shown in Figure (6).
The highest rate of infection was recorded during February $32.1 \%$ while the lowest rate was recorded during April (7.49\%) as show in Figure (7).

For improvement the diagnosis of aspirated material from CL lesion were stained by using Giemsa stain and cultured on semi-solid media. It was found that $73 \%$ of samples were positive for Giemsa stain, while $27 \%$ were negative as shown in Figure (8).

The percentage of positive culture of Leishmania on semi-solid media was represented in Figure (9).

It was found that $43 \%$ of samples were positive while $57 \%$ were negative (no growth). Figure (10) shown types and percentages of secondary bacterial infection that isolate from CL lesions. It found that the most common bacteria was Staphylococcus epidermidis $55 \%$ following by staph aureus $33 \%$, Streptococcus pyogens $7 \%$ and Escherichia coli $5 \%$.

AL-TUZ district is regarded as rural area, there are many factors that play important role in presence and distribution of CL in this district area like presence of reservoirs animals like rodents, dogs, etc., presence of Marshes and some of houses are made of clay especially houses which in villages that belong to this district area. Even that AL-TUZ district is regarded as agriculture area that attracts and harboring many kinds of insects therefore people through their working for long time in the farms were more exposed to insects bite.

Form the total of 107 patients with CL were included in the study, $57 \%$ of patients were male, while $43 \%$ were female. This result was in agreement with that found by AL-Obaidi who carried on his study in Tikrit, Sarhan ER. Who carried on his study in Baghdad and 
Sharifi et al., who carried on his study in Iarn in contrast AL-Zaidawi who carried on his study in Tikrit he was found that the rate of infection in female was higher than in male. these differences may be explained due to difference in the number of population included in these groups of studies.

The incidence rate of infection by $\mathrm{CL}$ in patient were their ages above 15 years old was $57 \%$ while it was $43 \%$ in patients which were their ages $\leq 15$ years old. Male CL patients were their ages above 15 years old were represented in this study were $25.23 \%$ from 107 patients. Female CL patients were their ages above 15 years old $31.7 \%$ from 107 patients. this difference between these two groups of patients might be explained that female in this group of ages more exposed to insects bite than male patients in the same ages group and due to that most of worker in the farms were females and through our data we found that male CL patients were their ages $\leq 15$ years old they were $(31.7 \%)$ from all patients.
Female CL patients were their ages $\leq 15$ years old they were $(11.21 \%)$ from 107 CL patients, so incidence rate of infection in the male patients in this ages group is higher than in female in same ages group, the difference between these two groups might be related to habit of male patients in this ages group in playing without clothes even that swimming in the Marshes. This finding was in agreement with that found by AL-Obaidi in Tikrit and Hussein in Baghdad and EL-Gorban in Door town (AL-Obaidi, 2000).

Through our clinical study we observed that the proportion of CL patients which have ulcerative wet type lesions (ZCL) (63.5\%), higher than in the patients which have nodule dry lesions (ACL) (36.5\%) (Figure 5).this result may be explained due to the presence of reservoirs animals in large numbers in this area especially rodents and higher than in patients which have single lesion (42\%). This result could be explained that people more exposed to plebotomine sand flies and high rate of presence sand flies in this area.
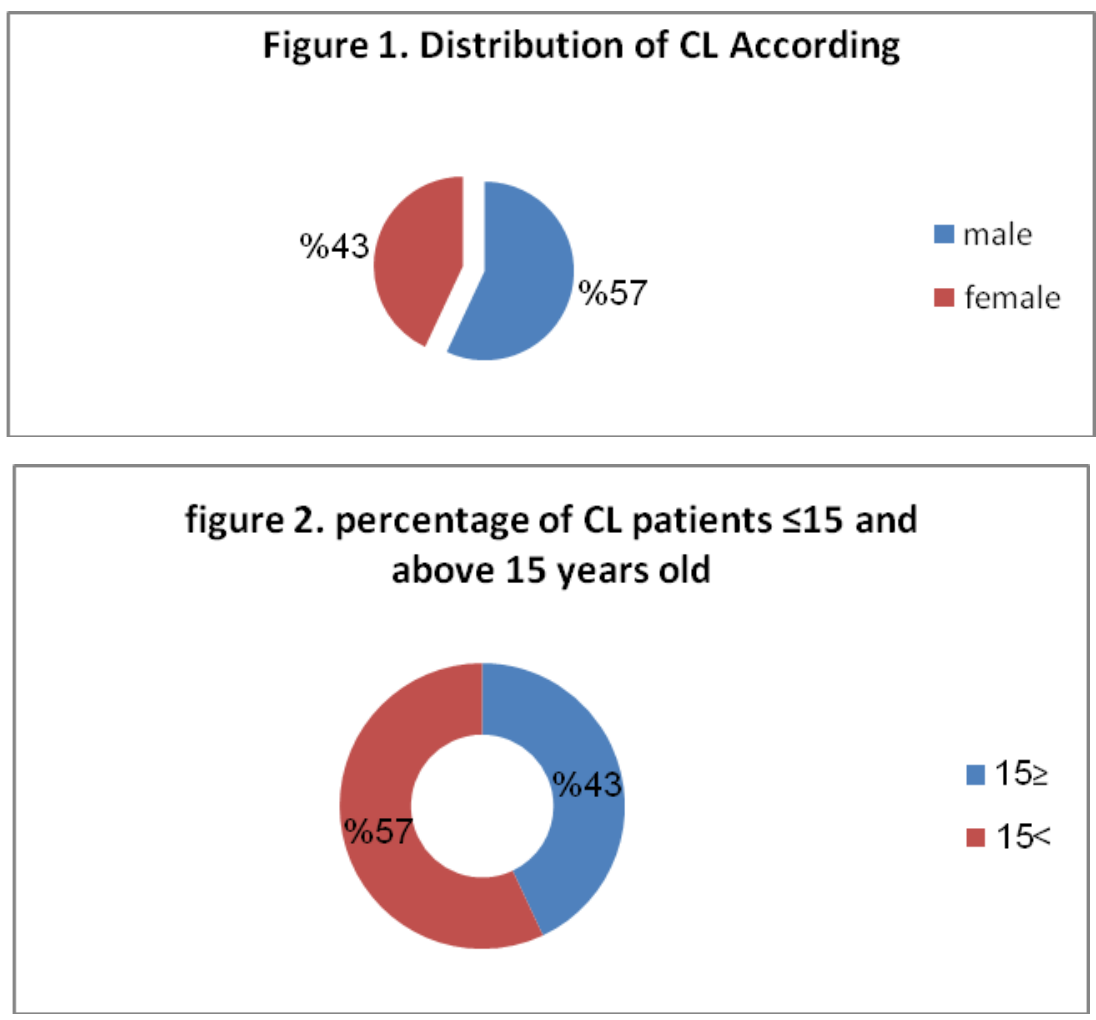


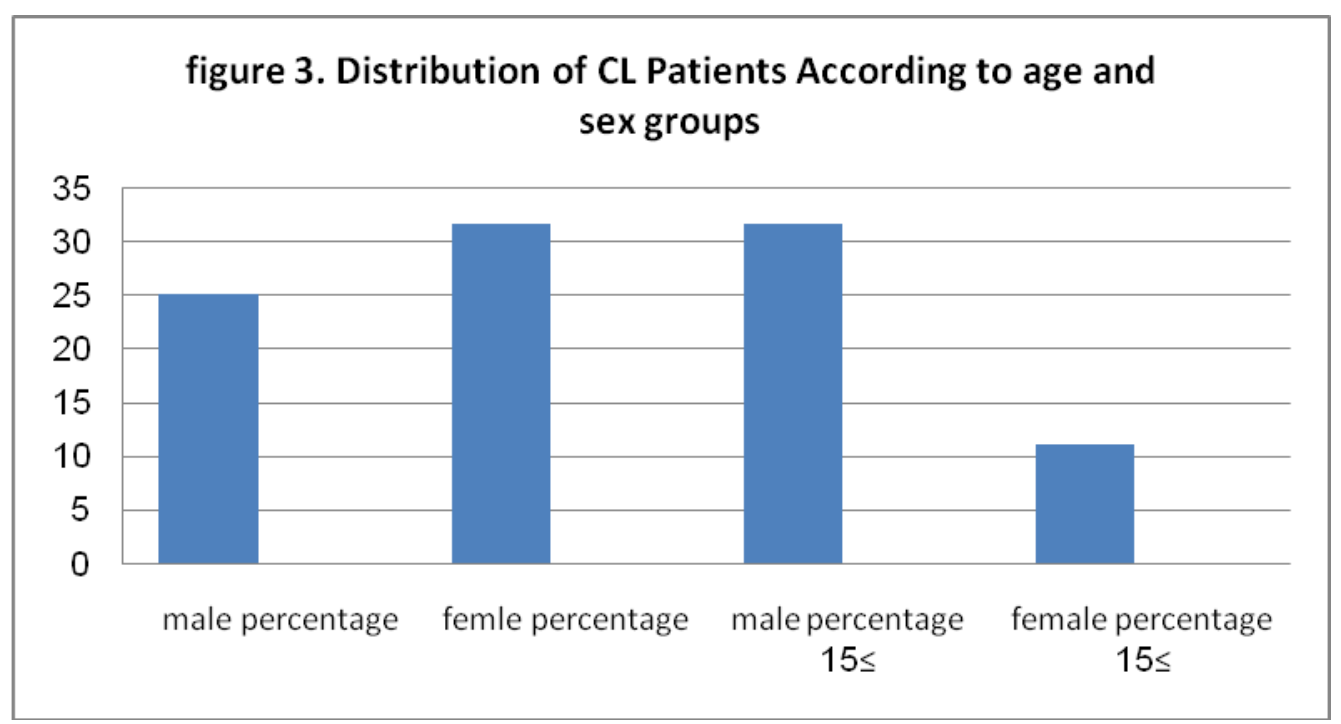

figure 4. Distribution of CL patients According to Number of lesions

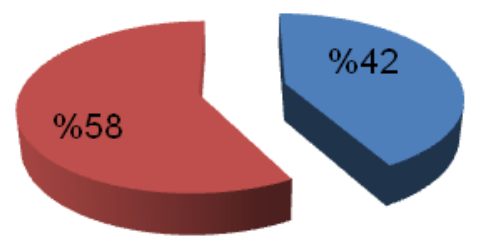

- single lesion

- multiple lesions

figure 5.Distribution of CL Patients According to Type of Lesions

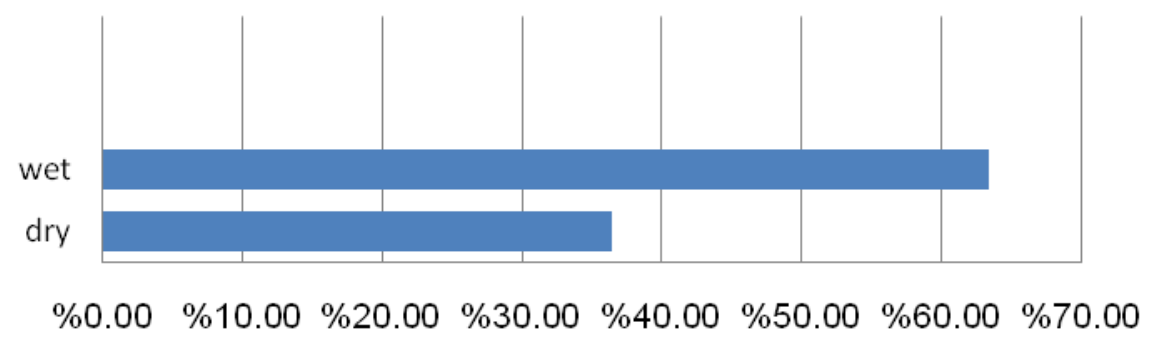


Figure 6. Distribution of skin lesions on Different parts of the Body of 107
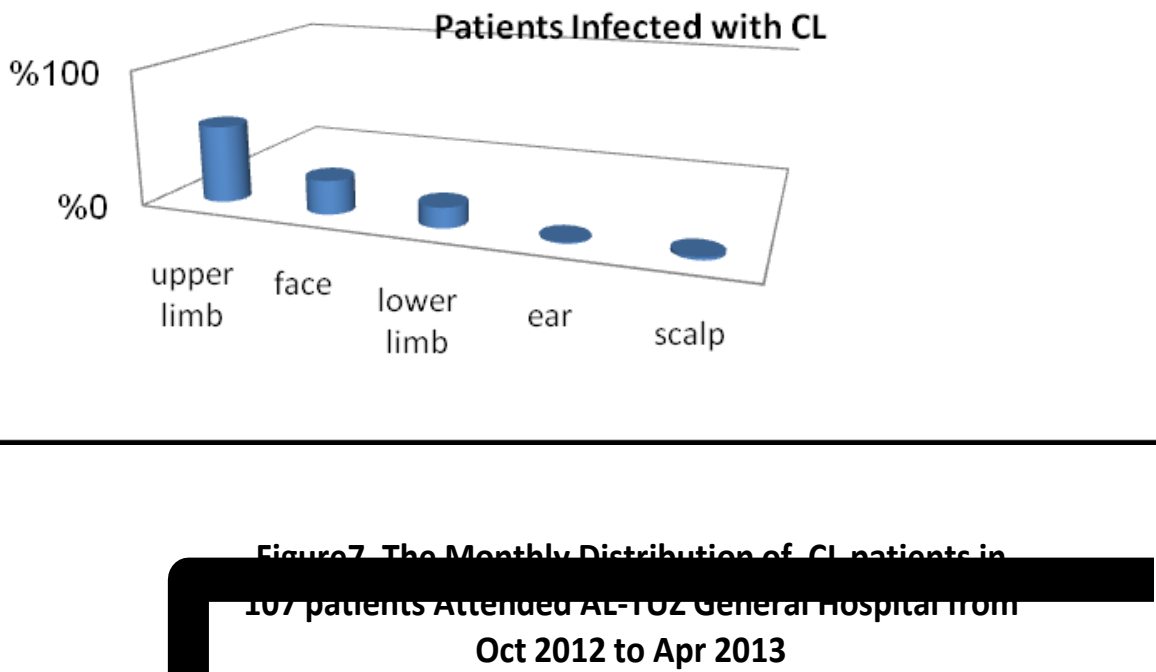

50

0

Oct Nov Dec Jan F'eb Mar Apr

Figure 8. The percentage of positive \&negative $\mathrm{CL}$ Cases in smears

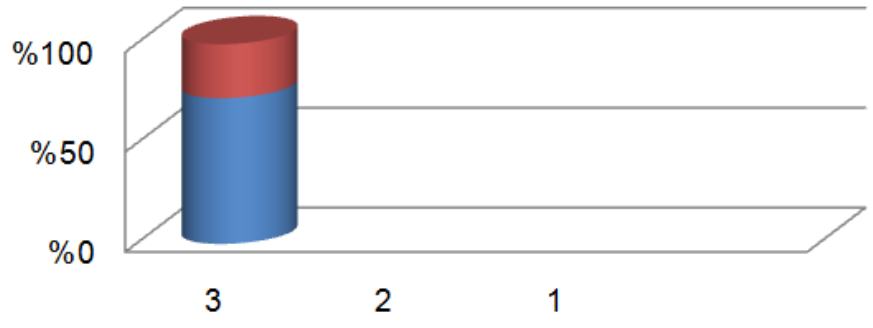

Figure 9.The percentage of positive \&negative CL

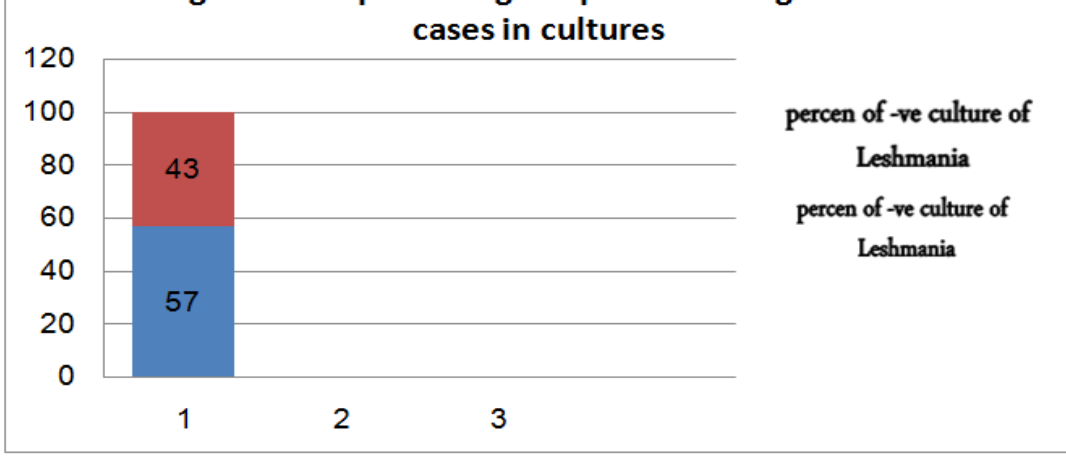




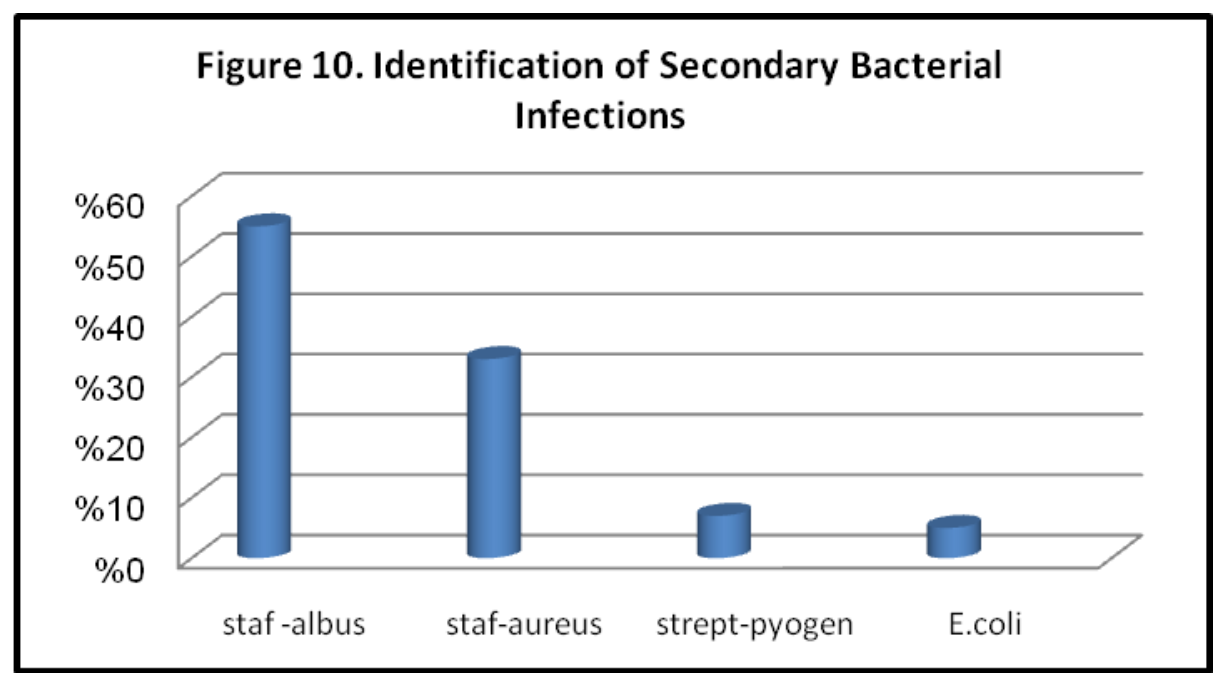

Regarding to distribution of CL lesions in this study we found that the higher proportion of the lesions were located on the upper limbs $(57 \%)$, face $(47 \%)$ and lower limbs (15\%) and less frequent on the scalp (2\%) and ear (1\%).

In comparison to the AL-Obaidi (Dedet et al., 2003) study he was found that the incidence rates of $\mathrm{CL}$ lesions were on upper limbs, lower limbs and less frequent in on the face and much less on the trunk respectively. In contrast to AL-Zaidaw, who reported that the face was more affected. These differences may be explained due to the habitant and habits of people concerned. Some of people prefer to sleep outdoors, the upper and lower limbs as well as the face being exposed to sand fly bites at night when the insects become more active. In general presence and distribution of lesion depend on exposed parts of body of susceptible host.

Regarding to the monthly distribution of CL patients, new cases tended to increase in Qctober and reach to maximum in January and February. The incidence rate of infection started to decline from March and reaches its lowest point in April. It was observed that the majority of CL patients were attended to ALTUZ between the months of Qctober and March. This result was in agreement with that found by AL-Obiadi. The differences in monthly distribution of CL patients might be related to activity of the sand flies, development of female insects and requirement of blood during their life cycle for maturation and development of eggs to complete their life cycle especially in spring season. The gaps between the bite and appearance of skin lesions might be related to long incubation period of Leishmaniasis (2-4 months).

To confirm the diagnosis of CL smears and cultures were used in this study, $73 \%$ of samples were positive while $27 \%$ were negative stained. The negative results might be due to long duration of lesions. Regarding to cultivation it was found that $43 \%$ of samples were positive, while $57 \%$ were negative (no growth). The negative results may be due to long duration of lesions, contamination by fungus, bacteria and even that the Leishmania spp regarded as fastidious microorganisms.

Secondary bacterial infection occurred in $42 \%$ of CL lesions. Most of bacteria were regarded as opportunistic microorganisms. Different kinds of bacteria that associated with CL lesions occurred with different proportions: Staphylococcus epidermids 55\%, Staphlyococcus aureus 33\%, Sreptococcus pyogen $7 \%$ and Escherichia coli $5 \%$. 


\section{References}

Ala a El-Deen AL-Awan. 2004. Health in Iraq. Baghdad, MOH, 34.

AL-Gorban, H.A. 1996. Comparison of the intralesional therapy of cutaneous Leishmamiasis. A dissertation submitted to the Collage of Medicine, University of Tikrit. As a requirement for the degree of Diploma in Primary of Health care.

AL-Obaidi, H.S. 2000. Microbiological \& Pharmacological studies with a Trial of vaccination against cutaneous Leishmaniasis. Ph.D. Thesis submitted to Collage of Medicine, University of Tikrit.

AL-Zaidawi, K.A. 1997. New approach for treatment of Cutaneous Leishmaniasis by manitol. Diploma dissertation, Collage of Medicine, University of Tikrit.

Ashford, R.W., Desjeux, P., de Raadt, P. 1992. Estimation of population at risk of infection and number of cases of Leishmaniasis. Parasitl Today, 8: 1045.
Communicable Disease Control, EMRO, 2003. WHO Office, Baghdad. WHO; 39-44.

Dedet, J.P., Pratlong, F. 2003. Leishmaniasis. In: Manson P, Cook GC, Zumla A, eds. Manson's Tropical diseases. $21^{\text {st }}$ ed. London: Saunders, 1339-64.

Hussian, A.K. 1993. Intra - lesional therapy of CL with hypertonic sodium chloride solution Diploma thesis submitted to Dermatology \& Venerology Dep. Collage of Medicine, University of Baghdad.

Sarhan, E.R. 1998. Study on Epidemology of Cutaneous Leishmaniasis in Baghdad. Msc Thesis submitted to College of Medicin, University of Baghdad.

Sharifi, I., Ferkeri, A.R. and Aflatonian, M.R. 1998. Cutaneous Leishmaniasis in primary school children in the Southeastern Iranian city of Bam, Bull. WHO, 76: 289-293.

William, H., Markle, and Khaldoun Makhoul. 2004. Cutaneous Leishmaniasis Recognition and Treatment. March 15. Americian Family Physician, WWW.aafp.org/afp.

\section{How to cite this article:}

Shujan R. Hassan. 2017. Epidemiological Study of Cutaneous Leishmaniasis in Tuz. Int.J.Curr.Microbiol.App.Sci. 6(1): 477-483. doi: http://dx.doi.org/10.20546/ijcmas.2017.601.056 